\title{
Investigating the Effectiveness of Mobile Peer Support to Enhance the Quality of Life of Older Adults: A Systematic Literature Review
}

\author{
https://doi.org/10.3991/ijim.v13i04.10525 \\ Murtaja Ali Saare ${ }^{(凶)}$, Azham Hussain
Universiti Utara Malaysia, Kedah, Malaysia
mmurtaja88@gmail.com \\ Wong Seng Yue \\ Universiti Malaya, Kuala Lumpur, Malaysia
}

\begin{abstract}
Aging is the biological, psychological, or social change that occur with the passage of time, which leads to functional impairment, and eventually chronic diseases. The number of people living older is rapidly increasing, and there is a natural decline in physical activity. The reduced mobility affects their daily life activities making them dependent on others for health. Therefore, mobile technologies such as m-health applications provide potential for enhanced health care among older adults. The present study highlights the factors that affect the adoption of smartphone applications, and potential factors such as mobile peer support can facilitate older adults to adopt latest technologies. However, previous studies have remained unsuccessful in explaining the moderating role of mobile peer support. Therefore, this paper aims to provide an insight with potential solution to the challenges of aging life, hence, enhancing their quality of life. This paper is only a conceptual explanation, which aims to identify the possible factors that influence their smartphone adoption using a systematic literature review on relevant peerreviewed papers. It is expected that this work will lead towards the empirical findings on the explanation of the interplay of the peer support to address the relationship of assistive mobile health applications and quality of life. This paper provides directions for future studies in improving the quality of life of older adults by using technology.
\end{abstract}

Keywords-Older adults, quality of life, m-health application, smartphone, mobile peer support.

\section{Introduction}

Technological development has increased the population of older adults as a result of improved public health [1] which is evident as there is an increase in world aging population. For example, In England there was an increase in older adults by $39 \%$ [2]. Similarly, In 2015 Malaysia had approximately 2.4 million individuals $(8.0 \%)$ aged 
60 and above; this number is expected to make up over $15 \%$ of the total population by [3] which has led the researcher's interest in the improvement of quality of life of older age For example, Canada's population was approximately 5 million in 2011; this number is expected to be doubled in the next 25 years [4] and In 2015, Malaysia had approximately 2.4 million individuals $(8.0 \%)$ aged 60 and above; this number is expected to make up over $15 \%$ of the total population by [3].

The term older adult is defined in the who as persons aged 65 years. Recent researchers has identified the subgroups of "older adults" as "younger old" (ages 6575), "older-old" (ages 75-85), and "oldest old" (ages 85+) [5]. Older adult experience age related changes both physical and cognitive. Physical changes associated with aging include declines in vision, hearing, and psychomotor coordination [6]. Similarly, cognitive changes consist of reduced attention span, declines in memory, and changes in spatial abilities are also observed.

There is an increasing likelihood of disease with age as older adult's population are easily affected by diseases such as high blood pressure, heart problems, overweight, and diabetes. For example, according to Centers for Disease Control and Prevention (CDC) 30.3 million people in US have diabetes. Diabetes is a fast-growing disease affecting approximately 400 million people in 1980 [7] and it is expected that it will affect 642 million people in 2040 [8]. Hence, diabetes is found as one of the primary cause of premature death worldwide [9]. Moreover, $80 \%$ of diabetes cases were found in developing countries [9] such as Malaysia. However, it is difficult for older adult to see a medical specialist daily, as older adults are dependent and require support to visit a clinic [10] which act a barrier to their wellbeing. Therefore, in order to overcome health [11], supporting independence [12], improving the wellbeing [10], and supporting the self-management of chronic diseases [13] technology plays a significant role and provide solutions for older adults[14]. Technology in the form of digital devices and/or applications can be used in various domains of everyday lives [15]. Assisted Technology (AT) is defined as: 'any device or system that allows an individual to perform a task that they would otherwise be unable to do, or increases the ease and safety with which the task can be performed' [16]. Assisted Technology (AT) offers a potential solution to this challenge of an ageing population such as through mobile health applications [17].

Previous studies have revealed that $80 \%$ of US citizens are mobile subscribers [18] it is expected that the number will increase to more than 256 billion or a third of world's population by 2018 [19]. However, not all age groups are accepting and using smartphones. For example only $18 \%$ of older adults have adopted to smartphone [20]. The possible reasons as revealed by literature is significant gap in terms of requirements of interface [21] as there is decline in cognition with age [22]. Moreover, the requirements of older adults are different from younger adults, and is poorly captured in the literature [23] as existing smartphone interface are based on suitability of younger adults who do not have cognitive decline [24]. As the requirements of older adults are different from younger adults [25]. Thus, there is a need to examine the patterns involved in technology adoption among older adults.

Since, older adults face technical difficulties, which are defined as "interruptions that individuals encounter when interfacing with technology"[26], they have searched 
for technical support to use smartphone [27]. As the interface of these devices are not made keeping in mind the requirement of this population, which elicit stress [28] they feel discouraged and confused [29]. Hence, to cope with such stress older adults look for resources such as social networks and [27] family and friends [30] who act as a facilitator in the learning process of technology-health application which can influence their quality of life.

A variable which affects the linkage between two or more variables is known as moderating variable, whereas moderation refers to the moderating effect on the linkage [31]. Therefore, the present study integrates mobile peer support as a moderator in the relationship between mobile-health applications and quality of life as it is a source of facilitation in the use of m-health application, which in turn will enhance their quality of life. The objective of present study is:

- To investigate the potential factors in the interface that affect the adoption of mhealth application.

- To examine the role of mobile peer support in the relationship between assistive mhealth application and quality of life.

\section{Methodology}

The present study used top down (review of the literature) approach to understand the problems in the interface of assistive m-health application that hinders the adoption, and hence, affects the quality of life.

\subsection{Literature search and database selection}

The first step used to search the relevant literature was choosing appropriate database IEEE Xplore, Science Citation Index, Scopus, Science Direct, Science Citation Index, and Web of Science. Database was searched using keywords related to the concepts of assistive mobile health technology, older adults, diabetes, mobile peer support and quality of life. The search was performed, using the search syntax as shown in the table below:

\begin{tabular}{|c|l|}
\hline Search & \multicolumn{1}{|c|}{ Keywords } \\
\hline Search \#1 & Assistive technology [title/abstract] AND older adults' [Title/Abstract] OR elderly \\
\hline Search \#2 & Older adults' [Title/Abstract] AND Quality of life [Title/Abstract] \\
\hline Search \#3 & $\begin{array}{l}\text { Assistive technology [title/abstract] AND older adults 'AND Quality of life } \\
\text { [Title/Abstract] }\end{array}$ \\
\hline Search \#4 & $\begin{array}{l}\text { Older adults' [Title/Abstract] AND Quality of life [Title/Abstract] AND Peer support } \\
\text { [Title/Abstract] }\end{array}$ \\
\hline
\end{tabular}

\subsection{Inclusion and exclusion criteria}

In the next step, we narrow down our search to be more specific and to narrow down and evaluated based on following criteria: 
- Articles, which were published between 2012 to 2018.

- Articles must be utilized a mobile phone as an intervention for their healthcare, involve or directly aim at older people quality of life of 45 years and over.

- Articles must address the question of how mobile services and applications that can be utilized to help improve, what are the barriers to mobile phone use how to overcome these barriers, what are the possible solutions to adopt to smartphones, and how technology can enhance the quality of life.

- Articles must include at least one combination of the search keywords (i.e. target group 1 mobile technology or mobile services and applications).

- Articles must be Scopus publications.

- Using several search keywords and increasing the complexity in the search inclusion criteria improves the quality of the search output.

\begin{tabular}{|c|c|c|c|c|c|c|c|c|}
\hline Journal & $\tilde{\bar{ก}}$ & $\stackrel{m}{\bar{N}}$ & $\stackrel{d}{\frac{\pi}{7}}$ & $\frac{n}{2}$ & 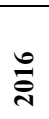 & 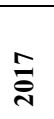 & $\stackrel{\infty}{\stackrel{\sim}{\leftrightarrows}}$ & 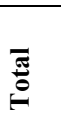 \\
\hline $\begin{array}{l}\text { International Journal of Human Computer } \\
\text { Interaction }\end{array}$ & 17 & 06 & 11 & 16 & 24 & 28 & 15 & 117 \\
\hline Behaviour \& Information Technology & 11 & 06 & 22 & 15 & 12 & 18 & 09 & 93 \\
\hline Journal of Assistive Technology & 35 & 31 & 13 & 12 & 15 & 48 & 34 & 188 \\
\hline $\begin{array}{l}\text { International Journal of Human-Computer } \\
\text { Studies }\end{array}$ & 42 & 47 & 52 & 60 & 51 & 86 & 82 & 420 \\
\hline Total & & & & & & & & 878 \\
\hline
\end{tabular}

\subsection{Evaluating the relevance}

In the third step, the researcher reviewed all relevant papers from both selected journals. Articles were selected based on the title of the paper, abstracts, methods, results and conclusion. In this step the researcher in decided whether or not a paper is relevant to this study. Once confirmed, then the full text articles were downloaded for thorough and detailed review. Furthermore, articles which were unclear either to include or exclude from the review process were resolved by discussing with a senior and knowledgeable researcher in the field.

\section{$3 \quad$ Results and Discussion}

Despite the fact that the relationship of m-health application and older adult's quality of life has been widely explained in the body of the literature from different perspectives for example according to sociological perspective any person or group can serve as a influencing factors for older adults to adopt smartphone applications [32], however, the peer support in the literature in terms of moderator remains less clear which is the contribution of the present study . 
The link between m-health application, mobile peer support and quality of life is dynamic in nature [33] specifically for applications that are associated with diabetes self-management. Czaja (2016) noted that older adult's cognitive decline significantly affects the quality of life is routed through the m-health application.

\subsection{Older adult use of assistive m-health application and mobile Peer support}

Older adult are the people that experience age-related physical and cognitive changes [23] which determines that older users will have different requirements in terms of interaction with technology [25]. Additionally, smartphone apps are helpful for older adults as they provide safety, security, privacy, and mobility (e.g., person location service, tracking devices, telecare monitoring, and an alarm system) [35] hence, supporting older adults' lives. Such solutions can enable their broad communication with others (e.g., social network and community platforms), hobbies (e.g., digital games adapted for older adults' requirements), or even religion and spirituality (e.g., services offering religious calendars, holy and prayer books, religious ringtones) [36]. Furthermore, older adults use assistive m-health application to integrate self-care activities for diabetes. Petrovčič, A. Rogelj, and V. Dolničar, (2018) examined the factors that plays significant role in the adoption of Assistive Smartphone Application among older adults, and their results showed that compatibility, effort expectancy, enjoyment, facilitating conditions and social influences significantly affected the older adult's use of smartphone application [37] [36].

Mobile Peer support help older adults to enhance their functioning or may buffer them from adverse outcomes [38]. Moreover, older adult accept technology as they are being motivated by their social surrounding such as purchasing technology relying on their peers which act as a "technology champions"[39]. Based on this discussion, we propose the following hypothesis.

Preposition 1: There is a significant relationship between $\mathrm{m}$-health application and peer support.

\subsection{M-health application and Quality of Life}

Assistive technology is defined as any device or system that allows an individual to perform a task that they would otherwise be unable to do with increased ease [40]. Smartphone applications can be used in various domains of everyday lives [10] such as medical and public health practices. Hence, support the health and wellbeing of older adults [12].

m-Health covers a variety of health and wellbeing apps which are designs for selfmanagement of health, wellbeing and long-term conditions and they may or may not be required to communicate with a clinician [10]. Ventola, (2014) reported that patients can actively participate in their own care by receiving services to change their health behaviour as application provides the opportunity to access health information and maintain contact with health care professionals [42]. These applications are especially useful for monitoring and diagnosing health conditions for those older 
adults for whom the physicians work far away. Smart phone applications are beneficial as there are variety of applications on fitness, chronic disease management (e.g. diabetes) [43]

However, there are certain factors which act as the barrier in the usability which limit level of adaptation of the m-health Application [44] such as age-friendly interface design [45], accessibility [46], and launchers [47].

Past research has also suggested that Assistive Smartphone Application has impacts on older adults that would increase, maintain, or improve their quality of life [35]. However, Inadequate inquiries have been done in the past to address the relationship of the Assistive Smartphone Application as a driver of quality of life in relation with older adults [48]. Older adult's cognitive decline can be the potential influential factor in the development of the quality of life as it has a direct effect on the Assistive Smartphone Application, but it remained unclear in the past literature, as systematic inquiry is needed to understand this relationship.

Therefore, based on the above-mentioned literature, it may be postulated that Mhealth application and older adult have direct link to define the quality of life of older adults as it remains an uncertain issue in the research. Thus, we propose the following preposition. Based on this discussion, we propose the following

Preposition 2: There is a significant relationship between M-health applicationand quality of life.

\section{Conclusion}

Considering the growing population and disease rate, and this article aims to shed light on the use of information technology such as m-health application to increase the quality of life of older adults. It conceptualizes the use of m-health application by incorporating some of the central concepts in the older adult and assistive mobile health application, and these concepts are defined in a way that permits prediction and understanding of quality of life. Findings suggested that age-related gaps in the interface of smartphone, which act as a barrier in the technology adoption. Therefore, these factors should be given some attention to accommodate the age-related changes to have optimal design for older adults that are user-friendly to offer promising healthcare.

\section{$5 \quad$ Future Work}

Although there has been significant research dedicated to the quality of life, however there is certainly still a plethora of opportunities for further studies in this field. It is expected that the present study will draw the attention of future researcher to this important area and provide researchers with a foundation upon which future knowledge can be built. This framework would provide guidance for usability specialists, product designers, interaction designers, product manufacturers and others involved in the design and development of user interfaces when seeking an ultimate design solution to support quality of life of older adults using assistive [49], [50]. 


\section{References}

[1] M. M. Bujnowska-Fedak and I. Pirogowicz, "Support for e-health services among elderly primary care patients," Telemed. E-health, vol. 20, no. 8, pp. 696-704, 2014.

[2] N. Holliday, G. Ward, and D. Awang, "COCREATING WELLBEING: THE WARMNEIGHBOURHOODS ${ }^{\circ}$ AROUNDMETM EXPERIENCE,” PEER Rev. B. Proc., p. $177,2016$.

[3] S. S. Hasan, C. S. Kow, R. K. Verma, S. I. Ahmed, P. Mittal, and D. W. K. Chong, "An evaluation of medication appropriateness and frailty among residents of aged care homes in Malaysia: A cross-sectional study," Medicine (Baltimore)., vol. 96, no. 35, 2017. https://doi.org/10.1097/MD.0000000000007929

[4] J. Fontecha, R. Hervás, J. Bravo, and F. J. Navarro, "A Mobile and Ubiquitous Approach for Supporting Frailty Assessment in Elderly People,” J. Med. Internet Res., vol. 15, no. 9, p. e197, 2013. https://doi.org/10.2196/jmir.2529

[5] J. M. Pérez-Mármol, M. A. Ortega-Valdivieso, E. E. Cano-Deltell, M. I. Peralta-Ramírez, M. C. García-Ríos, and M. E. Aguilar-Ferrándiz, "Influence of upper limb disability, manual dexterity and fine motor skill on general self-efficacy in institutionalized elderly with osteoarthritis," J. Hand Ther., vol. 29, no. 1, pp. 58-65, 2016. https://doi.org/10.1016/j.jht.2015.12.001

[6] D. Hawthorn, "Possible implications of aging for interface designers," Interact. Comput., vol. 12, no. 5, pp. 507-528, 2000. https://doi.org/10.1016/S0953-5438(99)00021-1

[7] A. S. Jarab, T. L. Mukattash, A. Al-Azayzih, and M. Khdour, "A focus group study of patient's perspective and experiences of type 2 diabetes and its management in Jordan," Saudi Pharm. J., vol. 26, no. 3, pp. 301-305, 2018. https://doi.org/10. 1016/j.jsps.2018.01.013

[8] W. H. El-Tantawy and A. Temraz, "Management of diabetes using herbal extracts," Arch. Physiol. Biochem., pp. 1-7, 2017.

[9] 9 J. Apelqvist, "The Diabetic Foot Syndrome Today: A Pandemic Uprise," in The Diabetic Foot Syndrome, vol. 26, Karger Publishers, 2018, pp. 1-18.

[10] N. Holliday, G. Ward, and S. Fielden, "Understanding younger older consumers' needs in a changing healthcare market-supporting and developing the consumer market for electronic assisted living technologies,” Int. J. Consum. Stud., vol. 39, no. 4, pp. 305-315, 2015. https://doi.org/10.1111/ijcs.12192

[11] M. Jones and C. Rowbottom, "The role of telecare in overcoming social exclusion in older people," J. Assist. Technol., vol. 4, no. 3, pp. 54-59, 2010. https://doi.org/1 $\underline{0.5042 / \text { jat.2010.0493 }}$

[12] A. Pinkelman, M. Roll, and D. Greene, "Use of a Modified Canadian Occupational Performance Measure for Assistive Technology Outcomes in Postsecondary Education," Occup. Ther. Heal. care, vol. 30, no. 4, pp. 388-401, 2016.

[13] Y. Hu et al., "Different Ways of Engaging the End-Users in mHealth Services," eTELEMED 2018, p. 110, 2018.

[14] S. J. Czaja et al., "Factors influencing use of an e-health website in a community sample of older adults," J. Am. Med. Informatics Assoc., vol. 20, no. 2, pp. 277-284, 2013. https://doi.org/10.1136/amiajnl-2012-000876

[15] A. Hussain, M. A. Saare, O. M. Jasim, and A. A. Mahdi, "A Heuristic Evaluation of Iraq E-Portal,” J. Telecommun. Electron. Comput. Eng., vol. 10, no. 1-10, pp. 103-107, 2018.

[16] S. Deleonibus, Intelligent Integrated Systems: Devices, Technologies, and Architectures, vol. 1. CRC Press, 2014. https://doi.org/10.1201/b15600 
[17] M. Stellefson et al., "Reliability and Validity of the Telephone-Based eHealth Literacy Scale Among Older Adults: Cross-Sectional Survey,” J. Med. Internet Res., vol. 19, no. 10, 2017. https://doi.org/10.2196/jmir.8481

[18] A. Brem and E. Viardot, "Revolution in Innovation Management: The Digital Breakthrough," in Revolution of Innovation Management, Springer, 2017, pp. 1-16.

[19] P. Zheng, X. Liang, G. Huang, and X. Liu, "Mapping the field of communication technology research in Asia: content analysis and text mining of SSCI journal articles 1995-2014,” Asian J. Commun., vol. 26, no. 6, pp. 511-531, 2016. https://doi.org/10. $1080 / 01292986.2016 .1231210$

[20] W. R. Boot et al., "Computer proficiency questionnaire: Assessing low and high computer proficient seniors," Gerontologist, vol. 55, no. 3, pp. 404-411, 2015. https://doi.org/10.1093/geront/gnt117

[21] J. Poushter, "Smartphone ownership and internet usage continues to climb in emerging economies," Pew Res. Cent., vol. 22, 2016.

[22] J. Chin et al., "Cognition and health literacy in older adults' recall of self-care information," Gerontologist, vol. 57, no. 2, pp. 261-268, 2017.

[23] K. L. Young, S. Koppel, and J. L. Charlton, "Toward best practice in human machine interface design for older drivers: a review of current design guidelines," Accid. Anal. Prev., 2016.

[24] N. Azir Rezha, Z. Maksom, and C. P. Naim, "Tackling design issues on elderly smartphone interface design using activity centered design approach,” ARPN J. Eng. Appl. Sci, vol. 9, pp. 1190-1196, 2014.

[25] S. G. Joshi and H. Bråthen, "SUPPORTING NEW INTERACTIONS WITH PAST EXPERIENCES ANCHORED IN MATERIALS," IADIS-INTERNATIONAL J. Comput. Sci. Inf. Syst., vol. 11, no. 2, pp. 74-89, 2016.

[26] P. Choudhury, E. Starr, and R. Agarwal, "Machine Learning and Human Capital: Experimental Evidence on Productivity Complementarities," 2018.

[27] M. Anderson and A. Perrin, "Technology use among seniors," Washington, DC Pew Res. Cent. Internet Technol., 2017.

[28] J. Stout and M. Moshtaghi, "A Game for Eliciting Trust Between People and Devices Under Diverse Performance Conditions," in Computer Games: 6th Workshop, CGW 2017, Held in Conjunction with the 26th International Conference on Artificial Intelligence, IJCAI 2017, Melbourne, VIC, Australia, August, 20, 2017, Revised Selected Papers, 2018, vol. 818, p. 172.

[29] B. Schuurman, "Research on Terrorism, 2007-2016: A Review of Data, Methods, and Authorship," Terror. Polit. Violence, pp. 1-16, 2018.

[30] I. Pettersson, P. Appelros, and G. Ahlström, "Lifeworld perspectives utilizing assistive devices: Individuals, lived experience following a stroke," Can. J. Occup. Ther., vol. 74, no. 1, pp. 15-26, 2007. https://doi.org/10.2182/cjot.06.05

[31] J. F. Dawson, "Moderation in management research: What, why, when, and how," J. Bus. Psychol., vol. 29, no. 1, pp. 1-19, 2014. https://doi.org/10.1007/s10869-013-9308-7

[32] C.-H. Hsiao and K.-Y. Tang, "Examining a model of mobile healthcare technology acceptance by the elderly in Taiwan," J. Glob. Inf. Technol. Manag., vol. 18, no. 4, pp. 292-311, 2015. https://doi.org/10.1080/1097198X.2015.1108099

[33] C. Siegel and T. E. Dorner, "Information technologies for active and assisted livingInfluences to the quality of life of an ageing society," Int. J. Med. Inform., vol. 100, pp. 32-45, 2017. https://doi.org/10.1016/j.ijmedinf.2017.01.012

[34] S. J. Czaja, "Long-term care services and support systems for older adults: The role of technology.," Am. Psychol., vol. 71, no. 4, p. 294, 2016. https://doi.org/10.1037/a0040258 
[35] I. Plaza, L. Martín, S. Martin, and C. Medrano, "Mobile applications in an aging society: Status and trends,” J. Syst. Softw., vol. 84, no. 11, pp. 1977-1988, 2011. https://doi.org/10. 1016/j.jss.2011.05.035

[36] S. Helal, C. Giraldo, Y. Kaddoura, C. Lee, H. El Zabadani, and W. Mann, "Smart phone based cognitive assistant," in UbiHealth 2003: The 2nd International Workshop on Ubiquitous Computing for Pervasive Healthcare Applications, 2003.

[37] A. Petrovčič, A. Rogelj, and V. Dolničar, "Smart but not adapted enough: Heuristic evaluation of smartphone launchers with an adapted interface and assistive technologies for older adults," Comput. Human Behav., vol. 79, pp. 123-136, 2018. https://doi.org/10.1016/j.chb.2017.10.021

[38] T. K. Dao, L. Donghyuck, and H. L. Chang, "Acculturation level, perceived English fluency, perceived social support level, and depression among Taiwanese international students," Coll. Stud. J., vol. 41, no. 2, pp. 287-296, 2007.

[39] A. Reynolds and T. F. Osborne, "Promoting Technology Adoption and Engagement in Aging," Using Technol. to Improv. Care Older Adults, 2017.

[40] D. Curran, "Parents of Autistic Children and Their Experiences With Assistive Technology." Northeastern University, 2017.

[41] C. L. Ventola, "Mobile devices and apps for health care professionals: uses and benefits," Pharm. Ther., vol. 39, no. 5, p. 356, 2014.

[42] A. Rocha et al., "Innovations in health care services: The CAALYX system," Int. J. Med. Inform., vol. 82, no. 11, pp. e307-e320, 2013. https://doi.org/10. 1016/j.ijmedinf.2011.03.003

[43] G. R. Husted, J. Weis, G. Teilmann, and P. Castensøe-Seidenfaden, "Exploring the Influence of a Smartphone App (Young with Diabetes) on Young People's SelfManagement: Qualitative Study," JMIR mHealth uHealth, vol. 6, no. 2, 2018. https://doi.org/10.2196/mhealth.8876

[44] B. Abdulrazak, Y. Malik, F. Arab, and S. Reid, "PhonAge: adapted smartphone for aging population," in International Conference on Smart Homes and Health Telematics, 2013, pp. 27-35. https://doi.org/10.1007/978-3-642-39470-6 4

[45] A. Petrovčič, A. Rogelj, and V. Dolničar, "Smart but not adapted enough: Heuristic evaluation of smartphone launchers with an adapted interface and assistive technologies for older adults," Comput. Human Behav., 2017.

[46] M. C. N. Carvalho, F. S. Dias, A. G. S. Reis, and A. P. Freire, "Accessibility and usability problems encountered on websites and applications in mobile devices by blind and normalvision users," in Proceedings of the 33rd Annual ACM Symposium on Applied Computing, 2018, pp. 2022-2029. https://doi.org/10.1145/3167132.3167349

[47] A. Petrovčič, A. Rogelj, and V. Dolničar, "Smart but not adapted enough: Heuristic evaluation of smartphone launchers with an adapted interface and assistive technologies for older adults," Comput. Human Behav. volBehav.p. 123-136, 2018. https://doi.org/10. 1016/j.chb.2017.10.021

[48] M. S. Alsaqer, "Helping Elderly with Wayfinding \& Physical Exercise: Development of Assistive and Persuasive Mobile Interventions Sensitive to Elderly Cognitive Decline." The Claremont Graduate University, 2017.

[49] S. Liu and S. Joines, "Developing a framework of guiding interface design for older adults," in Proceedings of the Human Factors and Ergonomics Society Annual Meeting, 2012, vol. 56, no. 1, pp. 1967-1971. https://doi.org/10.1177/1071181312561291

[50] A. Hussain, E. O. C. Mkpojiogu, and Z. Hussain, "Usability evaluation of a web-based health awareness portal on Smartphone devices using ISO 9241-11 model," J. Teknol., vol. 77, no. 4, pp. 1-5, 2015. 


\section{$7 \quad$ Authors}

Murtaja Ali Saare is a Ph.D. School of Computing, Sintok, Universiti Utara Malaysia, Kedah, Malaysia (UUM). He holds a masters degree in computer science. His research interests include aging and cognition, e-health, and human-computer interaction. He has published his work in reputable Scopus indexed journals.

Azham Hussain is the Associate Professor of Software Engineering at School of Computing, Sintok, Universiti Utara Malaysia, Kedah, Malaysia. He is the founder and head of Human-Centered Computing Research Group, which is affiliated with the Software Technology Research Platform Center at School of Computing, Universiti Utara Malaysia. Azham Hussain is a member of the US-based Institute of Electrical and Electronic Engineers (IEEE), and actively involved in both IEEE Communications and IEEE Computer societies.

Dr Wong Seng Yue is a senior lecturer at the Centre for the Initiation of Talent \& Industrial Training, Universiti Malaya, Kuala Lumpur, Malaysia. He received PhD degree in information science. He current researches include mobile augmented reality in STEM, gamification and e-health with industry 4.0.

Article submitted 2019-01-27. Resubmitted 2019-03-15. Final acceptance 2019-03-15. Final version published as submitted by the authors. 